What, then, are our duties towards insulin dependent diabetic patients in relation to home blood glucose monitoring ? Doctors' attitudes will vary, but all patients should be made aware of the technique and, if interested, be given or loaned equipment for a trial period. Those choosing to continue will need further guidance. The choice between a reflectance meter and strips suitable for direct visual reading is an individual one, but whichever method is used the patient's competence should be assessed. There are sources of potential error, ${ }^{21}$ and repeat checking of technique and accuracy is necessary. Patients will tire quickly of producing large numbers of results if they do not understand or are not told how to use them, so arrangements are needed for individual follow up by a physician. The results may point towards the need for radical changes in insulin treatment, and if these are not undertaken monitoring becomes no more than a record of poor control. All this means that if more patients are to use self monitoring effectively, demands on staff time will increase and efficient schemes will be needed for the education of patients. The emergence of the specialist nursing teacher is a step forward, but all those concerned with diabetic patient care, including family practitioners, can play a part by becoming familiar with self monitoring techniques.

What, finally, are the financial implications for patients and the National Health Service? Reflectance meters cost around $£ 80$ and strips retail at about 26 p each (NHS cost about $15 p$ each). Blood monitoring equipment is not available on prescription, and though some patients receive supplies through hospital pharmacies others bear the full cost. If we believe that near normal blood glucose concentrations are desirable, it seems illogical to provide on prescription urine testing apparatus which, though cheaper, can detect only frank hyperglycaemia and to penalise those who prefer to use blood testing. And, in balancing the costs with the advantages of blood glucose monitoring, we must be aware of patient preferences and needs, which are not reflected in objective indicators of control.

P M BELL Senior registrar

K WALSHE Research fellow

Metabolic Unit,

Royal Victoria Hospital,

Belfast BT12 6BA

${ }^{\prime}$ Rollo J. An account of two cases of diabetes mellitus with remarks as they arose during progress of the cure. London: C Dilly, 1797.

${ }^{2}$ Malone JI, Hellrung JM, Malphus EW, Rosenbloom AL, Grgic A Weber FT. Good diabetic control-a study in mass delusion. $\mathcal{F}$ Pediatr 1976;88:943-7.

${ }^{3}$ Shenfield GM, Steel JM. Urinary glucose testing by diabetic patients. Practitioner 1977;218:147-50.

4 Sönksen PH, Judd SL, Lowy C. Home monitoring of blood-glucose. Method for improving diabetic control. Lancet 1978;i :729-32.

${ }^{5}$ Walford S, Gale EAM, Allison SP, Tattersall RB. Self-monitoring of blood-glucose. Improvement in diabetic control. Lancet 1978;i:732-5.

${ }^{6}$ Tchobroutsky G. Relation of diabetic control to development of microvascular complications. Diabetologia 1978;15:143-52.

' Webb DJ, Lovesay JM, Ellis A, Knight AH. Blood glucose monitors: a laboratory and patient assessment. Br Med f 1980;280:362-4.

" Reeves ML, Forhan SE, Skyler JS, Peterson CM. Comparison of methods for blood glucose monitoring. Diabetes Care 1981 ;4:404-6.

${ }^{9}$ Worth RC, Harrison K, Anderson J, Johnston DG, Alberti KG. A comparative study of blood glucose test strips. Diabetes Care $1981 ; 4: 407-11$.

${ }^{10}$ Kerner W, Rosak C, Navascues I, et al. Ein neuer teststreifen für die blutzuckerkontrolle. Dtsch Med Wochenschr 1982;107:1346-9.

11 Judd S, Sönksen PH. Teaching diabetic patients about self-management Diabetes Care 1980;3:134-9.

12 Danowski TS, Ohlsen P, Fisher ER, Sunder JH. Parameters of good control in diabetes mellitus. Diabetes Care 1980;3:88-93.

${ }^{13}$ Stubbs SM, Brudenell JM, Pyke DA, Watkins PJ, Stubbs WA, Alberti KGMM. Management of the pregnant diabetic: home or hospital, with or without glucose meters? Lancet 1980;i:1122-4.
"Worth R, Home PD, Johnston DG, et al. Intensive attention improves glycaemic control in insulin-dependent diabetes without further advantage from home blood glucose monitoring: results of a controlled trial. Br Med f 1982;285:1233-40.

${ }^{15}$ Kelly CA, Barrett EJ, Nash J. Home monitoring and self-management of diabetes in a rural population. Ir Med f 1981;74:321-4.

${ }^{16}$ Bell PM, Walshe $\mathrm{K}$. Impact of home monitoring on diabetic lifestyle and blood glucose control. Practitioner (in press).

17 Baum JD. Home monitoring of diabetic control. Arch Dis Child 1981; $56: 897-9$.

${ }^{18}$ Schiffrin A, Belmonte MM. Multiple daily self-glucose monitoring: its essential role in long-term glucose control in insulin-dependent diabetic patients treated with pump and multiple subcutaneous injections. Diabetes Care 1982;5:479-84.

19 Holman RR, Turner RC. Diabetes: the quest for basal normoglycaemia. Lancet $1977 ; \mathrm{i}: 469-74$.

${ }^{20}$ Paisey RB, Bradshaw $\mathrm{P}$, Hartog $\mathrm{M}$. Home blood glucose concentrations in maturity-onset diabetes. Br Med f 1980;280:596-8.

${ }^{21}$ Peacock I, Tattersall R. Methods of self monitoring of diabetic control Clin Endocrinol Metab 1982;11:485-501.

\section{Chest pain: heart or gullet?}

Compared with the two centuries since Heberden's elegantly clear description of cardiac pain, recognition of the oesophagus as the origin of recurrent chest pain is relatively recent. Walter Verdon's quaint monograph ${ }^{1}$ of 1920 was, perhaps, the first milestone. Public consciousness of the fact that chest pain may be a harbinger of death tends to concentrate both lay and medical attention on the heart in any patient with discomfort in the chest, and the patient may have extensive cardiological investigations before alternative explanations are considered. This is understandable, for the clear identification of cardiac pain is not always easy, and no one wishes to pass off as trivial a complaint which may all too soon disclose its true origin to the coroner's pathologists and which might be treatable by drugs or coronary bypass surgery.

Yet hazards exist in an entirely cardiological approach to chest pain, for inevitably this suggests to the patient that he may harbour a mortal illness within his breast. If in fact he has a benign oesophageal condition this may amount to a cruel deception, with a potential for cardiac neurosis. A recent study in Cardiff ${ }^{2}$ showed that only two thirds of patients admitted to hospital because of anterior chest pain turned out to have ischaemic heart disease, similar to our figure in Worcester 17 years ago $^{3}$ and that of William Evans ${ }^{4}$ in London before that. In as many as a fifth of patients the pain may have originated in the oesophagus.

The reason that so many patients with non-cardiac chest pain reach hospital with a diagnosis of heart disease is easy to understand. General practitioners and doctors in accident departments are likely to expect the hospital to resolve any doubts lest blame results. Such an attitude is reasonable provided that a firm diagnosis is quickly reached, for a patient may react adversely to medical doubt, and even a hint of a cardiac disability may have grave repercussions on his future health (mental and physical) and employment.

Many disorders may produce chest pain simulating that of coronary artery disease. These include spondylosis, root pains, chest wall pains, zoster, and hyperventilation, but some lesion of the oesophagus is the most common alternative. The most important step in differentiating cardiac from oesophageal pain is a careful history with an emphasis on discriminatory features. The Cardiff study ${ }^{2}$ showed that reliance on Heberden's ${ }^{5}$ original features of angina-retrosternal location, strangling quality, relation to exertion, and accompaniment 
by mental anxiety-is insufficient, for of 77 patients with pain of this character, a fifth had an oesophageal origin for their pain. Nevertheless, of 23 patients with non-anginal pain, only one had a myocardial infarct. A few patients may describe the oesophageal pain as gripping, or radiating down their arm, or precipitated mainly by exercise; some patients with ischaemic heart disease may complain of burning discomfort or experience most of their pain in bed; but most patients will cause no great diagnostic problem if the history is carefully sought.

Add to this careful history a clinical examination which may find cardiac abnormalities and a standard electrocardiogram and only a few patients will remain undiagnosed. For some of these, in whom the pain is infrequent and whose initial investigation shows no hint of cardiac disease, a label of "chest pain ?cause" may be the most practical solution. ${ }^{6}$ If the doctor or patient finds that unsatisfactory further investigation is desirable.

If ischaemic heart disease is uppermost in the doctor's mind he will first turn to exercise electrocardiography, though he should bear in mind the interpretative difficulties. If still in doubt some would proceed to coronary angiography, but as oesophageal pain is a likely alternative an equally logical-and certainly safer-response would be to seek abnormalities in the gullet. Pain-producing oesophageal disorders range from the common reflux oesophagitis to rarities such as achalasia and diffuse spasm; other motor abnormalities may be discovered but these may not always be identified as the definite cause of the patient's pain.

A barium swallow and meal examination may display gross lesions such as achalasia or classical diffuse oesophageal spasm, suggest lesser degrees of abnormal oesophageal motility in the form of tertiary contractions, or may sometimes show an unexpected ulcer; the examination is less satisfactory for recognising gastro-oesophageal reflux. Fibreoptic endoscopy and oesophageal biopsy will find oesophagitis and ulcers, but endoscopy is a poor guide to problems of motility.

Perfusion of the oesophagus with acid, a simple inexpensive test, will usually precipitate the patient's pain if it is caused by reflux oesophagitis, and any doubts about cardiac problems may be resolved by simultaneous electrocardiography. ${ }^{78}$ Acid gastro-oesophageal reflux may be accurately delineated by intraoesophageal $\mathrm{pH}$ monitoring. ${ }^{9-11}$

Oesophageal manometry will uncloak some motility disorders causing chest pain, but the technique is not available widely enough in Britain and anyway poses problems of interpretation. Now that gammacameras are more generally accessible isotopic oesophageal transit studies may come into more use as a screening test for oesophageal motor abnormalities, ${ }^{12}$ though any suspected abnormality will need further investigation by manometry. Davies and his colleagues have shown that some oesophageal motor abnormalities causing pain may be provoked by injecting ergometrine during manometric studies, ${ }^{13}$ but the potential dangers of this drug in provoking coronary artery spasm makes its routine use unwise. Edrophonium has similar benefits and disadvantages. ${ }^{14}$ Safer provocative agents are needed, for even when pain indisputably arises from oesophageal motor abnormalities these are transient and elusive, readily escaping detection by tests done between $\stackrel{\text { W }}{T}$ episodes of pain.

When the whole gamut of cardiac and oesophageal investiga- $\frac{\mathbb{2}}{c}$ tion has been run there will remain two groups of patients still posing problems-those for whom there is no answer, and $\bar{\Xi}$ those who have both oesophageal and cardiac pain.

The "insoluble group" may frustrate their doctors, but this $\mathbb{D}$ should not make them victims of overenthusiastic diagnostic 0 endeavours. A decision to halt tests, assurance that they have

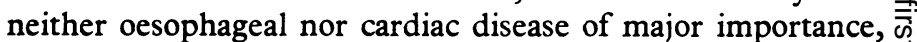
and perhaps symptomatic relief with analgesics should be 0 sufficient. The unfortunate patients with both oesophageal and cardiac pains are potentially more difficult unless they (or their $\frac{\bar{c}}{\frac{5}{\sigma}}$ doctor) can learn to discriminate between them. All too often $\stackrel{\Phi}{\mathscr{D}}$ the fear of heart disease leads to multiple unnecessary hospital admissions for successive episodes of pain. More than anything $\vec{\circ}$ else these patients need an understanding general practitioner who is available to calm their anxieties and to treat the pains $\vec{\omega}$ appropriately.

As William Heberden wrote ${ }^{15}$ after clearly delineating angina pectoris, ". . . the breast is often the seat of pains which are distressing sometimes even from their vehemence, oftener from their duration, as they have continued to tease the patient for $\omega_{-}$ six, for eight, for nine, and for 14 years. There have been $\omega$ several examples of their returning periodically every night. ... There has appeared no reason to judge that they proceed from $\overrightarrow{0}$ any cause of much importance to health . . . or that they lead $\frac{}{5}$ to any dangerous consequences."

JOHN R BENNETT 은

Consultant Physician,

Hull Royal Infirmary,

Hull HU3 2JZ

1 Verdon W. Angina pectoris. Brighton: Moulton, 1920.

"Davies HA, Jones DB, Rhodes J. "Esophageal angina" as the cause of chest pain. FAMA 1982;248:2274-8.

${ }^{3}$ Bennett JR, Atkinson M. The differentiation between oesophageal and cardiac pain. Lancet 1966;ii:1123-7.

+ Evans W. Faults in the diagnosis and management of cardiac pain. Br Med f 1959 ; : 249-54.

${ }^{5}$ Heberden W. Some account of a disorder of the breast. Medical Transac- 3 iions of the College of Physicians of London 1772;2:59-67.

"Wilcox RG, Roland JM, Hampton JR. Prognosis of patients with "chest pain ?cause." $\mathrm{Br}$ Med $\mathcal{F} 1981 ; \mathbf{2 8 2}: 431-3$.

- Bernstein LM, Baker LA. A clinical test for esophagitis. Gastroenterology $1958 ; 34: 760-81$

${ }^{3}$ Bennett JR, Atkinson M. Oesophageal acid-perfusion in the diagnosis of precordial pain. Lancet 1966;ii:1150-2.

${ }^{y}$ DeMeester TR, Johnson LF. The evaluation of objective measurements of gastroesophageal reflux and their contribution to patient management $\delta$ Surg Clin North Am 1976;56:39-53.

11) Stanciu C, Hoare RC, Bennett JR. Correlation between manometric and $\mathrm{pH}$ tests for gastro-oesophageal reflux. Gut 1977;18:536-40.

' Branicki FJ, Evans DF, Ogilvie AL, Atkinson M, Hardcastle JD. Ambula- N tory monitoring of oesophageal $\mathrm{pH}$ in reflux oesophagitis using a port- $\sigma$ able radio telemetry system. Gut $1982 ; 23: 992-8$.

12. Russell COH, Hill LD, Holmes ER, Hull DA, Gannon R, Pope CE. 을 Radionuclide transit: a sensitive screening test for esophageal dys- $N$ function. Gastroenterology 1981;80:887-92.

${ }^{13}$ Davies AH, Kaye MD, Rhodes J, Dart AM, Henderson AH. Diagnosis of oesophageal spasm by ergometrine provocation. Gut $1982 ; 23: 89-97$.

'4 London RL, Ouyang A, Snape WJ Jr, Goldberg S, Hirshfeld JW Jr, Cohen S. Provocation of esophageal pain by ergometrine or edrophonium. Gastroenterology $1981 ; 81: 10-4$.

Heberden W. Commentaries on the history and cure of tisease. London: T Payne, 1802 